\title{
Barriers to oral health care utilization in Ibadan, South West Nigeria
}

\author{
Ajayi $\mathrm{DM}^{1}, *$ Arigbede $\mathrm{AO}^{2}$
}

1. Department of Restorative Dentistry, Faculty of Dentistry, College of Medicine, University of Ibadan, Oyo State, Nigeria

2. Department of Restorative Dentistry, Faculty of Dentistry, College of Health Sciences, University of Port Harcourt, Rivers State, Nigeria

\begin{abstract}
Background: Barriers to oral health utilization are many, but those that are significant for our environment are not yet clear. The current study was designed to identify and graduate the barriers to receipt of oral health care among a cross-section of patients attending our centre. We also investigated the influence of socio demographic factors on the highly rated barriers. Methods: This cross-sectional study was conducted among patients visiting UCH, Ibadan using a self-administered questionnaire. Socio-demographic variables and oral health care seeking behaviour were requested and in addition, the respondents were asked to rank 11 listed barriers to receipt of oral health care and any other barriers they may think of in order of strength. Factor analysis was employed in order to identify four factors with the highest loading. The mean scores were compared using t-test and one-way ANOVA and the level of significance was set at 0.05

Results: Only 400 questionnaires were properly filled (84.9\%) out of the 471 that were administered. The mean age of these participants was $37.85 \pm 15.38$ years. Most of the respondents (55.8\%) consulted the dentists only when there was pain while $109(27.3 \%)$ had never visited the dentist. Fear of dental injection, cost of treatment, feeling of insecurity when the dentist is operating and disturbing noise from dental drill were the major barriers. There was a statistically significant association between age groups and feeling of insecurity $(\mathrm{p}=006)$.
\end{abstract}

Conclusion: The major barriers to oral health care utilization among our patients were fear related.

Key words: Barriers, dental anxiety, oral health care

African Health Sciences 2012; (4): 507 - 513 http://dx.doi.org/10.4314/ahs.v12i4.17

\section{Introduction}

Oral diseases qualify as major public health problems owing to their high prevalence and incidence in all regions of the world, and as for all diseases, the greatest burden of oral diseases is on disadvantaged and socially marginalized populations. The severe impact in terms of pain and suffering, impairment of function and effect on quality of life is also tremendous. ${ }^{1}$ Unlike in several developed countries ${ }^{2,3}$ dental caries and periodontal diseases are still highly prevalent in Nigeria. ${ }^{4}$ Oral health disparities refer to the existence of differences in the incidence, prevalence, mortality and burden of oral diseases and other adverse health conditions as well as the use of health care services, among specific population groups. ${ }^{5}$ The traditional concept of access to oral

\begin{tabular}{l}
\hline *Corresponding author: \\
Abiodun Olabisi Arigbede \\
Department of Restorative Dentistry \\
Faculty of Dentistry, College of Health Sciences \\
University of Port Harcourt, Rivers State \\
Nigeria \\
Telephone: +2347055736436 \\
Email: arisabbey@yahoo.ca, arisabbey@gmail.com
\end{tabular}

*Corresponding author:

Abiodun Olabisi Arigbede

Department of Restorative Dentistry

Faculty of Dentistry, College of Health Sciences

University of Port Harcourt, Rivers State

Nigeria

Email: arisabbey@yahoo.ca, arisabbey@,gmail.com health care refers to a patient ability to obtain or make use of oral health care. ${ }^{6}$ Factors external to the patient like adequacy of dental workforce and ability to pay for care were the primary determinants of access. Currently however, discussion of access takes into account factors internal to the patients like the perceived need for care, cultural peculiarities, language barriers, in addition to factors external to the patients. ${ }^{6}$

The sources of the barriers that the patient experience in relation to accessing oral health care are said to arise from their life experiences and psycho-social factors. These factors may include: age, gender, education, ethnicity, language, perception of need, anxiety states, and feeling of vulnerability. ${ }^{7}$ Others may include: cost of treatment, health status of the individual, disability, transportation, residence/ rurarity, adequacy of dental workforce and beliefs and charisma of dental health care personnel. ${ }^{6}$ From this list of factors, four main groups of barriers have been identified. These are dental anxiety, expensive nature of dental treatment, perception of need and lack of access. ${ }^{7}$ In the recent times, reluctance of a cross-section of the public to utilize oral health care 
in the light of their awareness of possible HIV crossinfectivity in the clinical setting is becoming an issue. ${ }^{8}$ This latest addition to the plethora of existing barriers to receipt of oral health care appears to be widening the existing gap between need and demand for oral health care. Our experience shows that many more patients are asking questions about the sterility of dental equipment and instruments during clinical procedures.

There is an important difference between the need for oral health care and the demand for it. ${ }^{6}$ A good understanding of the barriers that prevent people from seeking appropriate and timely oral health intervention is important when designing outreach activities that would bridge the gap between the need for care and the amount of care sought. Access to oral health care for some segments of the population is said to be complex and not easily resolved. ${ }^{6}$

The major factors acting as barriers to high level of utilization of oral health care services in Nigeria are not clear at the moment. Nigeria is a developing country with poor health care infrastructure, inadequate number and skewed distribution of health care personnel in favour of the urban communities. The economy is weak and provision of social services is far below average. Since oral health care is an important aspect of general health, studies designed to investigate these barriers are needed if the desire to overcome the unacceptable high tooth mortality and morbidity arising from caries related illness in developing countries like Nigeria is to be achieved.

The study was designed to identify and rank the barriers to receipt of oral health care among a cross-section of patients attending the Dental centre of University College Hospital (UCH), Ibadan. We also investigated the influence of socio demographic factors on the highly rated barriers. This information is necessary before an effective dental public health programme against the barriers to oral health care utilization could be designed for our environment.

\section{Methods}

This cross-sectional study was conducted among patients attending dental centre, $\mathrm{UCH}$, Ibadan. UCH is a renowned specialist hospital located in the Western part of Nigeria. A structured anonymous selfadministered questionnaire was employed as the instrument for data collection. The questionnaire requested for information on age, gender, educational background and dental visit behavior of the respondents. The respondents were also requested to list in order of importance the factors which they think constitute barriers to accessing regular oral health care services. A number of reported barriers like having no dentist around, no time, transportation problem, fear of pain, feeling of insecurity, uncomplimentary remarks about dental treatment, noise from dental instrument and fear of injection were outlined for the respondents in no particular order to reduce mental stress. Other barriers that were listed include: dental instrument are frightening, fear of contracting infection and the perceived expensive nature of dental treatment. They were also encouraged to include those factors which may not be listed, but which they think deter them from regular uptake of oral health care services.

The questionnaire was pretested for clarity, and understanding of the concept after a content validity/logical validity evidence was done by two consultants. However, the validity coefficient was not calculated. The questionnaires were randomly distributed in the waiting hall of Dental Centre, University College Hospital (UCH) Ibadan among patients who were 16 years and above and who agreed to participate in the study. All the questionnaire items were explained and clarified to the participants before the distribution. Respondents returned completed questionnaires at the centre. The sample size was chosen by convenience. Confidentiality and anonymity of the respondents was guaranteed and the ethical clearance for the study was obtained from the joint University of Ibadan and University College Hospital Ethical Review Committee.

\section{Statistical analysis}

The data was entered into a micro computer and analyzed using SPSS for Windows version 16.0, (SPSS Inc Chicago Illinois, USA). Descriptive statistics was performed on the socio-demographic variables. In addition, the respondents were asked to rate the eleven suggested barriers to utilization of dental services and any other they might include. The ranking was from one to eleven, with one being the highest rank. However, this ranking was reversed during data entry in order to give maximum weight to the barrier with the highest ranking. The barriers were then rated according to their mean scores. Factor analysis was employed in order to identify four factors (about a third of the total) with the highest loading. The means of their scores were later compared across certain socio-demographic and

African Health Sciences Vol 12 Issue 4 December 2012 
clinical variables, using t-test and one-way ANOVA and the level of significance was set at 0.05.

\section{Results}

All the administered questionnaires (471) were returned, but only 400(84.9\%) were correctly and completely filled. Incompletely filled questionnaires were rejected. The mean age of the participants was $37.85 \pm 15.38$ years, the age range was $16-78$ years

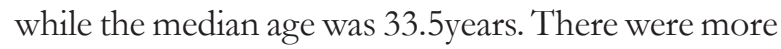
females $(55.5 \%)$ than males $(44.5 \%)$ and $57.5 \%$ of the respondents had higher education. Most of the respondents $(55.8 \%)$ consulted the dentists only when there was pain while 109(27.3\%) had never visited the dentist before the time of study (table 1).

Table 1: Socio demographic characteristics of the respondents

\begin{tabular}{lcr}
\hline $\begin{array}{l}\text { Mean Age }=37.85 \pm 15.38 \text { years } \\
\text { N=400 }\end{array}$ & \\
\hline Variables & Frequency & \multicolumn{1}{c}{$\%$} \\
\hline Gender & & \\
Male1 & 78 & 44.5 \\
Female & 222 & 55.5 \\
Age Group & & \\
16-39years & 245 & 61.3 \\
40-64years & 123 & 30.8 \\
$\geq 65$ years & 32 & 8.0 \\
Marital status & & \\
Single & 187 & 46.8 \\
Married & 200 & 50.0 \\
D/S/W & 13 & 3.2 \\
Education & & \\
None & 9 & 2.3 \\
1 $^{\circ}$ Education & 11 & 2.8 \\
$2^{\circ}$ Education & 52 & 13.0 \\
Post 2 ${ }^{\circ}$ (Not HND/University) & 87 & 21.8 \\
$\geq$ HND/University & 230 & 57.5 \\
No Response & 11 & 2.8 \\
Previous dental consultation & & \\
No & 109 & 27.3 \\
Twice a year & 36 & 9.0 \\
Once a year & 29 & 7.3 \\
Once in two years & 3 & 0.8 \\
\hline
\end{tabular}

The result on ranking of barriers is as shown in Table 2. Fear of experiencing pain, fear of dental injection, cost of treatment and fear of contracting infection respectively were the barriers with the highest means of scores while having no access to dentists and transportation problems constituted the weakest barriers. However, when factor analysis was used for extraction, the four variables with the highest loading were, fear of dental injection( loading 0.75, $\%$ variance explained $22.3 \%$ ); dental treatment is expensive( loading $0.70, \%$ variance explained $14.2 \%$ ); feeling of insecurity when dentist is operating in the mouth( loading $0.75, \%$ variance explained $10.9 \%$ ); and disturbing noise from dental instrument( loading $0.75, \%$ variance explained $9.7 \%$ ). No additional barrier was included by any of the respondents.

\section{Factor analysis was conducted to rank the barriers}

Fear of dental injection did not appear to differ statistically among the different categories studied, though the proportion was slightly higher in the females, in younger age group, less educated and among those that never visited dentists. The expensive nature of dental treatment appeared to be of greater concern to the males, to the middle aged, to the less educated, to the Divorced; separated or widowed and to those who have had previous dental consultation. However, none of these showed a statistical significant relationship with the cost of treatment (table 3).

The association between the other two barriers (that is, feeling of insecurity during intraoral procedures and disturbance from noise generated from dental instruments) and the selected characteristics is shown in table 4 . The disturbing noise from dental instruments did not appear to differ statistically among the various categories studied, though the proportion was slightly higher among the elderly patients and those that never had previous dental consultation. Furthermore, the feeling of insecurity during dental procedures was higher among the males, the elderly, the more educated, the married e.t.c. in the respective categories, though only the age group was statistically significant $(\mathrm{p}=0.06)$. 
Table 2: Ranking of the barriers

\begin{tabular}{lcllr}
\hline Barrier & No of respondents & Sum of scores & Mean & SD \\
\hline No dentist around & 397 & 1478 & 3.72 & 3.26 \\
No time & 399 & 2313 & 5.80 & 3.68 \\
Transport problem & 398 & 1654 & 4.16 & 2.87 \\
$\begin{array}{l}\text { Fear of pain } \\
\text { Feel insecure }\end{array}$ & 400 & 3049 & 7.62 & 5.46 \\
Uncomplimentary & 390 & 2292 & 5.73 & 2.52 \\
$\begin{array}{l}\text { remarks about } \\
\text { dental instrument/ }\end{array}$ & & 2389 & 5.99 & 2.74 \\
$\begin{array}{l}\text { treatment } \\
\text { Noise from }\end{array}$ & 398 & & & \\
$\begin{array}{l}\text { dental instrument } \\
\text { Fear of injection }\end{array}$ & 400 & 2144 & & \\
$\begin{array}{l}\text { Dental instruments } \\
\text { are frightening }\end{array}$ & 399 & 2911 & 5.39 & 2.50 \\
$\begin{array}{l}\text { Fear of contracting } \\
\text { infection }\end{array}$ & 400 & 2583 & 7.27 & 2.55 \\
$\begin{array}{l}\text { Dental treatment is } \\
\text { expensive }\end{array}$ & 400 & 2704 & 6.47 & 2.55 \\
\hline
\end{tabular}

Table 3: Fear of injection and cost of dental treatment by selected characteristics

\begin{tabular}{|c|c|c|c|c|}
\hline \multirow[b]{2}{*}{ Variables } & \multicolumn{2}{|c|}{ Fear of injection } & \multicolumn{2}{|c|}{ Dental treatment is expensive } \\
\hline & Mean (SD) & P value & Mean (SD) & P value \\
\hline \multicolumn{5}{|l|}{ Gender } \\
\hline Male & $7.2(2.5)$ & 0.53 & $6.9(3.6)$ & 0.19 \\
\hline Female & $7.3(2.6)$ & & $6.8(3.7)$ & \\
\hline \multicolumn{5}{|c|}{ Age group (years) } \\
\hline $16-39$ & $7.4(2.6)$ & 0.06 & $6.8(3.7)$ & 0.81 \\
\hline $40-64$ & $7.2(2.4)$ & & $7.0(3.6)$ & \\
\hline $65+$ & $6.3(2.7)$ & & $6.6(3.6)$ & \\
\hline \multicolumn{5}{|l|}{ Education } \\
\hline$<$ HND/University & $7.4(2.6)$ & 0.52 & $7.2(3.7)$ & 0.22 \\
\hline HND/University & $7.2(2.5)$ & & $6.7(3.6)$ & \\
\hline \multicolumn{5}{|l|}{ Marital status } \\
\hline Single & 7.1(2.7) & 0.39 & $7.0(3.7)$ & 0.78 \\
\hline Married & $7.4(2.4)$ & & $6.8(3.6)$ & \\
\hline $\begin{array}{l}\text { Divorced, separated, } \\
\text { or widowed }\end{array}$ & $6.8(2.2)$ & & $7.2(3.8)$ & \\
\hline \multicolumn{5}{|c|}{ Previous dental consultation } \\
\hline Yes & $7.1(2.5)$ & 0.06 & $6.9(3.9)$ & 0.71 \\
\hline No & $7.7(2.6)$ & & $6.8(3.5)$ & \\
\hline \multicolumn{5}{|l|}{ How frequently } \\
\hline Never & $7.7(2.6)$ & 0.24 & $6.6(3.6)$ & 0.40 \\
\hline Regular & $6.8(2.4)$ & & $7.7(3.6)$ & \\
\hline Irregular & $7.0(2.6)$ & & $6.8(3.6)$ & \\
\hline
\end{tabular}

ANOVA was employed to compare the means 
Table 4: Feeling insecure during intraoral procedure and disturbance from noise generated from dental instruments by selected characteristics

\begin{tabular}{|c|c|c|c|c|}
\hline \multirow[b]{2}{*}{ Variables } & \multicolumn{2}{|c|}{$\begin{array}{l}\text { Feeling insecure during } \\
\text { procedures }\end{array}$} & \multicolumn{2}{|c|}{ Noise from dental instrument } \\
\hline & Mean (SD) & $P$ value & Mean (SD) & P value \\
\hline \multicolumn{5}{|l|}{ Gender } \\
\hline Male & $5.8(2.7)$ & 0.52 & $5.4(2.6)$ & 0.68 \\
\hline Female & $5.6(2.4)$ & & $5.3(2.3)$ & \\
\hline \multicolumn{5}{|l|}{ Age group (years) } \\
\hline $16-39$ & $5.7(2.4)$ & 0.006 & $5.3(2.4)$ & 0.53 \\
\hline $40-64$ & $5.5(2.5)$ & & $5.4(2.6)$ & \\
\hline $65+$ & $7.0(3.0)$ & & $5.9(3.0)$ & \\
\hline \multicolumn{5}{|l|}{ Education } \\
\hline$<$ HND/University & $5.9(2.6)$ & 0.14 & $5.4(2.6)$ & 0.95 \\
\hline HND/University & $5.6(2.4)$ & & $5.4(2.4)$ & \\
\hline \multicolumn{5}{|l|}{ Marital status } \\
\hline Single & $5.5(2.5)$ & 0.21 & $5.4(2.4)$ & 0.51 \\
\hline Married & $6.0(2.4)$ & & $5.4(2.6)$ & \\
\hline $\begin{array}{l}\text { Divorced, separated, } \\
\text { or widowed }\end{array}$ & $5.5(2.2)$ & & $4.6(2.6)$ & \\
\hline \multicolumn{5}{|c|}{ Previous dental consultation } \\
\hline Yes & $5.7(2.5)$ & 0.86 & $5.4(2.5)$ & 0.57 \\
\hline No & $5.8(2.6)$ & & $5.4(2.6)$ & \\
\hline \multicolumn{5}{|l|}{ How frequently } \\
\hline Never & $5.2(2.4)$ & 0.45 & $6.2(2.4)$ & 0.18 \\
\hline Regular & $5.8(2.2)$ & & $5.3(2.4)$ & \\
\hline Irregular & $5.8(2.5)$ & & $5.4(2.5)$ & \\
\hline
\end{tabular}

ANOVA was employed to compare the means

\section{Discussion}

More female respondents (55.5\%) like in most other similar epidemiological studies ${ }^{9,10}$ were involved in this study. The elderly, constituted the least proportion of those requesting oral health care in this study as previously reported. ${ }^{11}$ This may be related to the fact that life expectancy in Nigeria is quite low $^{12}$, the elderly are clearly in the minority and besides it has been argued that the elderly often regard their oral complaints as minor compared to the chronic systemic conditions which they often suffer from. Our data showed that married and single individuals were almost equally represented. This parameter was rarely investigated in studies involving access to oral health care. Most of the respondents had postgraduate education. The distribution of the respondents in relation to their educational qualification brings to the fore the fact that our dental centre enjoys a lot of patronage from staff and students of the nearby University of Ibadan. Regarding oral health seeking behaviour, most of the patients visit dental clinic only when there was pain. This is not a new finding for our environment as oral health surveys from the sub-Saharan region show a very low utilization of oral health care services, and visits to dental-care facilities are said to be mostly undertaken for symptomatic reasons rather than for preventive care. ${ }^{4,13}$

Fear related conditions were observed as the major barrier to oral health care utilization among the studied population. Fear of dental injection constituted the barrier with highest ranking among the patients in this study. Avoidance of dental care due to fear is a well recognized phenomenon. Dental anxiety and fear of pain associated with dentistry are said to be stable over time despite advances in dental equipment, procedures and preventive measures. ${ }^{14,15}$ Associations have been found between dental fear and less frequent dental consultation as well as poorer oral health. ${ }^{14,15}$ Age and gender are among socio-demographic barriers to oral health care utilization. ${ }^{7}$ A consistent finding in relation to the characteristics of fearful people is that females and young adults have a greater prevalence of fear and more extreme fear than the males and the elderly 
respectively. ${ }^{14,15}$ This trend is also reproduced in this study. Fear of dental visit was rated very low in Ouagadougou. ${ }^{13}$ The reason for the unusual observation reported in Ouagadougou is not clear at the moment.

Expensive nature of dental treatment ranked next to fear in the current study particularly among men. Culturally, men are regarded as bread winners. In the face of global economy downturn particularly in a developing country like ours, it is not surprising that the cost of dental treatment is of much concern to the males. Low income/low educational qualification has for a long time been well recognized as a barrier to utilization of oral health care. ${ }^{6}$ In the Ouagadougou study, ${ }^{13}$ high cost of dental treatment was considered the strongest barrier. Guay ${ }^{6}$ also reported that high cost of dental treatment create circumstances that discourage access to care. Expensive nature of dental care has consistently remained a highly rated barrier to oral health utilization worldwide particularly in developing countries with ever dwindling resources and lack of robust medical insurance. In a previous study from our environment ${ }^{16}$, decline in clinic attendance was reported following increase in treatment charges. Traditional treatment of oral diseases is said to be extremely costly in several industrialized countries, and it is reported not to be feasible in most lowincome and middle-income countries. ${ }^{1}$

Our data also shows that feeling of insecurity when the dentist is operating in the mouth and disturbing noise from dental drill respectively were among the barriers highly regarded by our patients. The feeling of insecurity is significantly common among the elderly, but the reason for this is not clear. The reason why men felt more insecure than women may also be linked to the cultural expectation that men are supposed to be in control and since this is not the case during dental procedure, hence the feeling of vulnerability. This is in agreement with a previous study conducted in the $\mathrm{UK}^{7}$ where feeling of insecurity and disturbing noise from dental drill were among the barriers reported.

The feeling of insecurity may, however, be connected to the fear of contracting infection which was among the top rated barrier in this study, before the factor analysis was done. Unwillingness on the part of dental professionals to treat persons with HIV and AIDS due to fear of losing non- HIV infected patients had been reported. ${ }^{2}$ A previous report ${ }^{8}$ in our environment showed that about $30 \%$ of the participants were reluctant to receive oral health care because of fear of HIV cross-infection. A strict cross-infection control practices should continue to be provided in all health facilities and confirmed reports of lapses should be appropriately dealt with and treated with dispatch to restore public confidence. Pockets of reports from our environment about HIV cross-infectivity occurring in clinical environment particularly from blood transfusion exist in the literature. These types of reports often make the elites nervous when they seek medical and/or oral health care. ${ }^{17,18}$

Having no access to dentists and transportation problems constituted the weakest barriers in this study. This is not surprising, because this study was conducted in the metropolitan city of Ibadan with affordable transportation system and fairly distributed health care facilities. Besides, most of the respondents incidentally comprise highly educated individuals who sometimes come to the dental clinic in their pleasure cars. Residents living in rural areas are often identified with more unmet dental needs and lower utilization rates. ${ }^{6}$ Difficulty in gaining access to oral health facilities as a result of poor transport system, living in rural area, disability and poor systemic health have been well described in the dental literature. ${ }^{6}$

A major barrier that is worth discussing in our study is the issue of perceived need. Most of our patients indicated that they seek treatment only when there are symptoms. The primary reason why people seek health services is their belief that they need health care and that the situation will get worse without professional help. ${ }^{19}$ When speaking of access, we must consider both the availability of care and the patients' willingness to seek care. ${ }^{6}$ In a previous similar study ${ }^{12}$ conducted in Ouagadougou, one of the major reasons why the respondents did not seek dental care was because they believed that their oral symptoms were not serious enough and or they would go on their own. It is important to raise the level of dental awareness among our people especially among the disadvantaged and to inculcate preventive oral health care habits among them. Regular dental visit has been found to provide an opportunity for oral health professionals to promptly diagnose illness, provide primary preventive services and treat diseases and other health related problems. ${ }^{20}$

The barriers to oral health care utilization in our environment just like in other places are many and the need to prioritize based on the local experiences is, therefore, of immense importance. The problem of inadequate access to dental care for some segments of the population is a complex one. ${ }^{6}$ It has been proposed that psycho-social factors do not act independently of each other but combine to act in unison. ${ }^{6}$ The first step in problem resolution is to understand the circumstances as well as possible. ${ }^{6}$ and in this study we have found that the 
major barrier to utilization of dental care is fear related. The World Health Organization ${ }^{21}$ recommends that National health authorities should develop policies and measurable goals and targets for oral health. National public health programmes should incorporate oral health promotion and disease prevention based on the common risk factors approach. Control of oral disease and illness in older adults should be strengthened through organization of affordable oral health services, which meet their needs. For these laudable proposals to work, they must take cognizance of the prevailing barriers to receipt of oral health care.

\section{Conclusion}

The major barriers to oral health care utilization among our patients were fear related. The expensive nature of dental treatment as well as the disturbing noise of the dental drill was also of concern to the participants. We suggest improved oral health education in order to change the attitudes of people to oral health care.

\section{References}

1. Petersen PE. The World Oral Health Report 2003: continuous improvement of oral health in the 21st century- the approach of the WHO Global Oral Health Programme. Community Dent Oral Epidemiol 2003;31 Suppl 1:3-23 .

2. Nasir EF, Åstrøm AN, David J, Ali RW. Utilization of dental health care services in context of the HIV epidemic- a cross-sectional study of dental patients in the Sudan. BMC Oral Health 2009;9:30.

3. Kikwilu EN, Masalu JR, Kahabuka FK, Senkoro AR. Prevalence of oral pain and barriers to use of emergency oral care facilities among adult Tanzanians. BMC Oral Health 2008; 8:28.

4. Varenne B, Msellati P, Zoungrana C, Fournet F, Salem G. Reasons for attending dental- care services in Ouagadougou, Burkina Faso. Bull World Health Organization 2005; 83: 650-655.

5. Chattopadhyay A. Oral health disparities in the United States. Dent Clin North Am. 2008;52(2):297318.

6. Guay AH. Access to dental care. Solving the problem for underserved populations. J Am Dent Assoc. 2004; 135:1599-1605.

7. Freeman R. Barriers to accessing dental care: patient factors._Br Dent J. 1999 14;187(3):141-4. 1999; 187(3).

8. Arigbede AO, Ogunrinde TJ, Okoje VN, Adeyemi BF. Cross-infectivity of HIV Infection: Assessment of Behaviour of Patients Attending a University Dental Centre. The Internet Journal of Dental Science. 2009: 8(1).

African Health Sciences Vol 12 Issue 4 December 2012
9. Brothwell DJ, Jay M,Schönwetter DJ. Dental service utilization among independently dwelling older adults in Manitoba, Canada. J Can Dent Assoc. 2008; 74(2): 161-

10. Kikwilu EM, Masalu JR, Kahabuka FK, Senkoro AR. Prevalence of oral pain and barriers to use of emergency oral care facilities among adult Tanzanians. BMC Oral Health. 2008; 8:28.

11. Dolan TA, Atchison KA. Implications of access, utilization and need for oral health care by the non-institutionalized and institutionalized elderly on the dental delivery system. J Dent Educ. 1993; 57(12): 876-887.

12. UNICEF-At a glance:Nigeria-Statistics available @ http://www.org/infobycountry/Nigeriastatistics.ttml. Accessed on 03/08/11

13. Varenne B, Petersen PE, Florence F, Philippe Msellati P, Gary J, Ouattara S, Harang M, Salem $G$ Illness-related behaviour and utilization of oral health services among adult city-dwellers in Burkina Faso: evidence from a household survey. BMC Health Services Research 2006, 6:164.

14. Kanegane K, Penha SS, Munhoz CD, Rocha RD. Dental anxiety and salivary cortisol levels before urgent dental care. J Oral Sci. 2009;51(4):515-520.

15. Al-Omari WM,Al-Omiri MK. Dental anxiety among University students and its correlation with their field of study. J Appl Oral Sci. 2009; 17(3): 199-203.

16. Denloye OO, Bankole OO,Onyeaso CO. Dental health service utilization by children seen at the university College Hospital-an update. Odontostomatol Trp. 2004;24 (108):29-32

17. Oniyangi $\mathrm{O}$, Awani $\mathrm{B}$, Iregbu $\mathrm{KC}$, The pattern of paediatric HIV/AIDS as seen at the National Hospital Abuja Nigeria. Niger J Clin Pract. 2006;9(2):153-158.

18. Bugage MA, Aikhionbare HA. Paediatric HIV/ AIDS seen at Ahmadu Bello University Teaching Hospital Zaria, Nigeria. Ann Afr Med 2006; 5 (2): $73-77$.

19. Kiyak HA, Marisa Reichmuth M. Barriers to and enablers of older adults' use of dental services. J Dent Educ 2005; 69(9):975-986.

20. Denloye O,Ajayi DM, Bankole O, Popoola B. Dental service utilization among junior secondary school students in Ibadan, Nigeria. Pediatr Dent J. 2010;20(2):171-181.

21. Petersen PE, Yamamoto T. Improving the oral health of the older people: the approach of the WHO Global Oral Health Programme. Community Dent Oral Epidemiol. 2005; 33(2): 8192. 